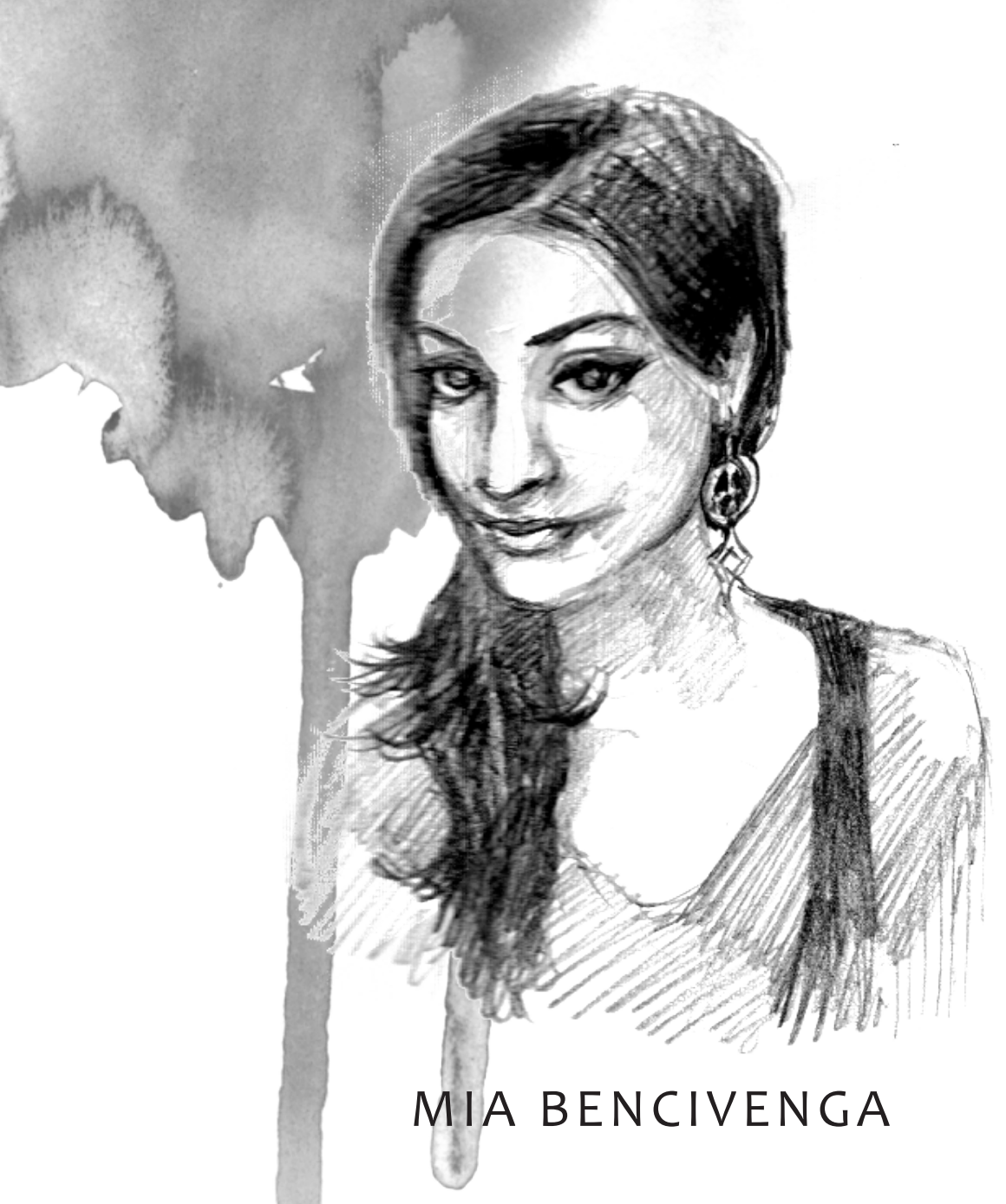

Mia Bencivenga studies Linguistics.

She's a vegetarian who doesn't eat fish sticks. She sometimes dismays with some of her essays... But she hopes that you will forgive this. 
FORBES \& FIFTH

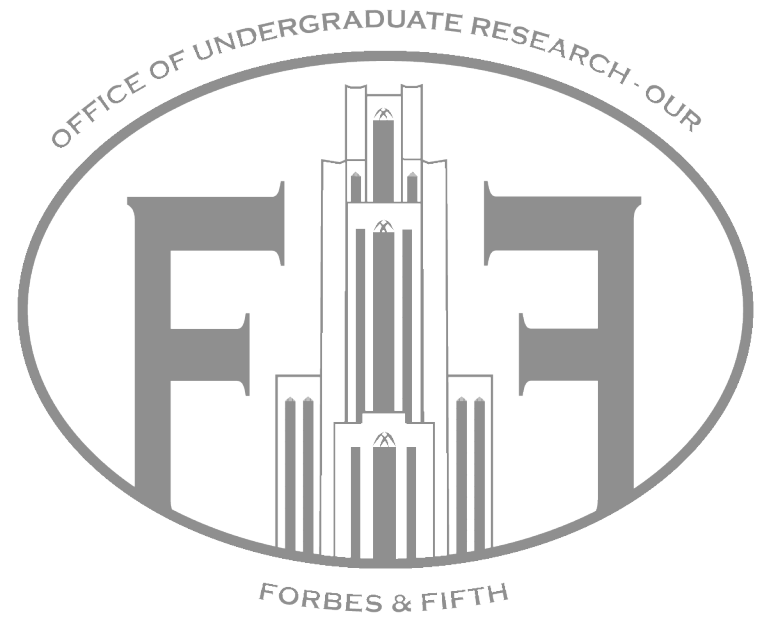




\section{How to Be a Perfect Feminine Being}

\section{Introduction: What Is the Perfect Feminine Being?}

Hello, friend. By reading this how-to guide, I am going to show you how to be the perfect feminine being. All that I have learned over my years of careful observation and analysis in female-centric environments $^{1}$ will be yours for the taking. And I pray that you will use your newfound feminine powers for good rather than evil, but hey, let's just say I'm not going to hold my breath. Would you like to know why?

Fact! From Eve, to Pandora, to some other third person that I can't think of, women across the board are historically excellent at unleashing hellfire and pain upon the masses. Be it eating a forbidden fruit (since studies show that women with more fiber in their diet weigh less) or opening up a jar (because you were dying to use it as a vase), with ladies, where there's a will, there's a way in screwing over humanity for an eternity.

But rest assured, one can correct these knavish tendencies through the proper adherence to my infinite wisdom, passed down to me through years of careful obedience to the one true Holy Book, Cosmopolitan, which I hope you will find insightful and meaningful, and not at all degrading and/or corrosive to your soul. Whatever your intentions may be with this material, you can rest assured that I have carefully designed this short guide into separate sections for maximum clarity and absorption.

But first, what is a "feminine being," as opposed to a "woman" or a "girl" or even a "lady?" I'm glad you asked! To put it simply, a feminine being is a female who can no longer hide behind Barbie Dreamhouse and rely on her My Little Ponies for friendship and support. Instead, she must fess up to the fact that she's an anime-obsessed, headgear-wearing stutterer who has never felt the amorous embrace of a male at seventeen mostly due to the fact that one of the boys caught her by her

1. Done, of course, in dive bars, junior high classrooms, and Hooters, respectively. 
locker planting kisses on a framed photo of Goku from Dragon Ball Z. ${ }^{2}$ However, this is not to say that she is all grown up either. A feminine being is not yet a woman, with you know, kids and bills... mom jeans... uh... PTA meetings? ${ }^{3}$ Rather, she is at that perfect in-between age where she is still very young, yet mature enough to engage in certain salacious activities without having to get lawyers involved. In short, a feminine being is in her prime. And she is most certainly not a "lady." You know why? Get ready for the truth machine to start pumping out the facts of life, as harsh and metallic as they may be.

No one wants to date a "lady."

"What?!" Cries one female. "Huh?!" Cries another. "Bitch, please!" Cries another in a significantly sassier manner. But I kid you not, I play no games. No one wants a Mary Poppins in their romantic life. ${ }^{4}$ Yeah. I said it. I may have just crushed your childhood dreams, and I'm okay with that. When you were a little girl, you may have wanted to be a woman like Mary Poppins; a straight laced magical nanny with a voice of an angel. But I'm here to say that that's a terrible thing to want, and it's only for your own good.

Here's why. When you're a lady, where's the pizzazz? The drama? The intrigue? Can you say mood killer? Love inhibitor? Apathy inducer? The term "lady" is too old fashioned to get the blood of a man to boil with passionate desire. It makes him feel the need to sit up straight and use proper noun adjective agreement and to say, "That Jersey Shore show is simple nonsense and corrupting the minds of our youth!" In short, it'll force him into being a free thinking gentleman who views women as people and not mere objects, and when that happens, people will no longer copulate out of pure lust, and then the human race ceases to exist! ${ }^{5}$

Some may say, "Okay then, Mia, if that's how it is, then let's just all break out our hot pants and dirtily dance in our short shorts, and

2. Classic high school anecdote! This is definitely not one of my personal experiences!

3. I have significantly less experience in this field.

4. Except those who enjoy her whimsical charm and kind-hearted positivity.

5. Either that, or people will start having sex out of love and fidelity. And I shudder to think of what the world will look like when that starts to happen. 
watch as our milkshake brings all the boys to the yard." Well, to those who would say that, I say, you are WRONG! Let me be absolutely clear. No one wants to date the village bicycle. This is for two reasons: 1 . Everyone has been for a ride. 2. It's an inanimate object and thus a terrible lover.

Masterfully crafted metaphors aside, women also cannot be too up front / comfortable / confident in their sexuality-it screams worldliness and self-acceptance, and there will be no other qualities that will disgust a man more. So what are we women to do? How are we to manage? What must we become in order to be unendingly desired in the classiest way possible?

Fear not! For the answer is easy. We must become a "perfect feminine being." Meaning, that one must have all of the qualities a woman can ever

"One must be both the village bicycle and Mary Poppins combined, in a type of cosmic fusion that will result in a woman so beautiful, so alluring, so impossibly wife-able, that even I in my completely heterosexual corpus cannot help but salivate over her and her utter perfection." hope to possess. One must be both the village bicycle and Mary Poppins combined, in a type of cosmic fusion that will result in a woman so beautiful, so alluring, so impossibly wife-able, that even I in my completely heterosexual corpus cannot help but salivate over her and her utter perfection. This woman makes Aphrodite look like a Plain Jane! She makes Gisele Bundchen look like a Typical Theresa! She makes Katy Perry look like an Archetypically-unappealing Anne! She's smart, but not too smart, beautiful, but in an approachable yet still semi-worship-able way, and so incredibly kind that she'll do everything in her power to make you smile, even if it means engaging in certain taboo enterprises with a trained naiveté that's almost disconcerting.

She is what everyone wants. She is what every magazine is telling us to be.

6. Nine years later and I still have no idea what this song means. 
In today's society, if there's anything we want as women, it's to know how we can be the best version of ourselves that we can be, no matter what the cost, no matter how hard the struggle. We do this not for ourselves, but rather, so that everyone who judges us unscrupulously can be amused at seeing us run around like chickens with their heads cut off, ${ }^{7}$ desperate to please and to show them that we are worthy of their love and affection. Love and affection being, of course, harsher criticism, because that's the only way we know that you truly care.

So without further ado, my fellow women, ${ }^{8}$ here is my guide on how to be the perfect feminine being.

\section{Chapter 1: Face, Waist, Taste!}

Okay, gals, we're going to start from the outside and work our way in. This is for a few reasons, the first being that, well, what's the first thing someone sees when they notice you? Why, your appearance, of course! Think about it. No one wants to amorously embrace a sack of potatoes, and if they do, well then, they have their own issues to work out. Rather, they want something prim, but still loose, polished, but still dirty. In short, she must be approachable, a typical type of girl, yet possess the humblest essence of godliness. But this is such a vague description. So what must a woman look like, in reality? To put it simply, she is freakish perfection mixed with sensual naiveté with a splash of "Oh, this old thing?"

Now that we have a nice, concrete image to work with, let's get to the perfecting! But oh, where do we even begin to discuss our imperfections and the ways in which we can correct them?

First, let's start with your face. And let's face it, it could use some work! $!^{9}$ From now on, makeup is your new best friend. You will

\footnotetext{
7. The latest fashion trend!

8. If there are any men reading this, please discontinue! To know our secrets is to deny yourself the pleasure of the surprise. And to any gay men reading this, please see the later section "Can I Have Friends?" for your role in all of this. Hint! It's small, shallow, and deeply stereotypical.

9. Extra tip! Perfect feminine beings must reinforce the fact that women aren't funny. And I do this in spades.
} 
wake up every morning and scrub your face clean with the latest products and scalpels to really get that fresh, youthful, slightly bloodied glow. For you see, that's how we'll get your cheeks so naturally rosy! You are going to want to apply foundation, then cover-up, followed up with a translucent powder to set what you've done so far, followed by a sweeping of clay the color of your skin over certain problem areas, which will be completed by spritzing a special type of French facial glue called Le Petit Cheval in order to hold everything in place. Elmer's mixed with water, vodka, and nail polish top coat in a spritzer bottle will also do the trick. After this small step is completed, we move on to your eyes.

As we've done before, we're going to try to keep it natural. We want the men folk to think that we arise majestically from our beds every morning with our eyelashes coated in wax that our eyelids make themselves. This can be achieved, but the pill you take for it gives you a strange urge to eat rubber and is extremely expensive, so I wouldn't recom"This can be achieved, but the pill you take for it gives you a strange urge to eat rubber and is extremely expensive, so I wouldn't recommend taking it until it's FDA approved/ you can find a cheap dealer on craigslist." mend taking it until it's FDA approved/you can find a cheap dealer on Craigslist. Until then, simply coat your eye lids in a shimmering powder not too different from your skin tone, followed by a dark brown pencil that you will run all around the eyes in a giant oval so as to draw attention to them subtly. Finally, you're going to want to get mascara, and for the next two to three hours, coat each individual eyelash until it almost hurts to have your eyes open due to the weight of your colossally huge and tarantula-esque, yet dainty, eyelashes.

Okay, so I'm getting the vibe that you're all, "But Mia! You're just giving us a series of impossible contradictions! None of this can be achieved! It's all a lie!"

And you know what I say to that? Fine. If you don't like it, go pick up the latest issue of Cats Are My Replacement for Children Since I 
Didn't Follow Mia's Advice Weekly written by that miserable old woman who lives down your street. ${ }^{10}$ Yeah, she was once a feminist. Now she's a feline-ist, living her life as she never hoped - alone and covered in cat urine. Is that what you want, huh?

Didn't think so. Another argument won. ${ }^{11}$

Also, no look is complete without a red lip. But a natural red lip. So skip the lipstick, and merely bite your own lip every second of every day. This easy trick also helps to plump them up so as to make them seem desirable enough to kiss, but keeps you so afraid of kissing due to the imminent pain, men will merely think you're hard to get, when in reality, you're suffering terribly. Remember the tried and true saying, "Pain is Beauty?" I want you to say that to your own reflection every morning in order to remind yourself that you are the perfect feminine being, as long as you're suffering.

After one has completed all of the other necessary rituals, like ensuring that your eyebrows are symmetrical and that your forehead is the proper ratio depending on the combined angle of your nose and ear width divided by the square root of gorgeous, we are going to move onto the rest of your body.

Okay, I don't know who you are or where you come from, but we all must look a certain way, regardless, if we wish to achieve perfect feminine being status. Now, some of us ${ }^{12}$ will not be able to fit into this mold since we may be built differently from the ideal. But don't be discouraged! Just do your best to meet me halfway here and there might be a husband in it for you! I mean, isn't that what we all want? A man who bases his love for us off of our completion of arbitrary rules that society sets for us, who also wants to be with us forever despite our whiny girlishness? Oh, to hit the jackpot like that is something I dream about every time I go to sleep. I know this because I toss and turn all night and wake up every morning in a cold sweat.

So as to remove any ambiguity, I will simply describe my vision of the ideal woman, as dictated to me by the holy popular culture, bitchings and sleaze be upon them.

The perfect feminine being has the legs of a giraffe, impossibly

10. Who, despite having new dentures, never smiles.

11. Most of my arguments are won after I use cat urine as a threat.

12. Er, um, all of us. 
long yet short enough so that a man can still feel as if he can dominate her. Her feet are small, delicate, like those of porcelain dolls, but also long and limber enough to force even the most foot adverse man into harboring a deep and somewhat unhealthy love for bunions. Her waist is so small, that it makes her round, lean, shapely, nonexistent hips and buttocks look as though they could birth even the biggest of babies. ${ }^{13}$ And her breasts are so perfectly proportional to her body ${ }^{14}$ that one can't help but ogle at them until you realize that you've been talking directly to her chest for five minutes and you can feel the hot hatred of her eyes boring into your skull.

That being said, let's move onto the last part of our most lengthy chapter: the importance of having good taste. By saying taste, I specifically mean the types of clothes you wear. Now, this can be tricky. Our initial instinct is follow the latest trends, wear the most expensive clothes, and wear the highest heels. Once again, my female friends, you have been led astray by your tiny, inefficient lady brains.

Here is my advice; look perfectly cute in the laziest way possible. Why? Remember, you simply wake up this way. In order to be perfect; one must be effortless, or at least, have the appearance of effort-

lessness. Here are your

"Here are your instructions: Go to Victoria's Secret, find your way to where they have all of the sweatpants and the polka dotted dogs. Go insane. Make the sales girl cry." instructions: Go to Victoria's Secret, find your way to where they have all of the sweatpants and the polka dotted dogs. Go insane. Make the sales girl cry. It can either be out of exultation, utter fear, or some freakish mixture of the two.

Buy everything. I'm talking sweat pants, perfumes, t-shirts, short shorts, bras, thongs, the whole she-bang. And I want you to wear this, daily, and nothing else. But we mustn't forget about your hair, which should be at this point, long, pin straight, and fried to the point of an onion ring. Do your best to wrangle it into a messy bun without

13. Could there be a more enticing thought?

14. And by perfectly proportional to her body I mean so utterly massive that smaller breasts orbit around her breasts because they have generated their own gravitational field. 
it disintegrating, and get your makeup just as we discussed above. If you do this, then I guarantee, you will be the ideal feminine being. At least on the outside. The rest however, still needs a ridiculous amount of work. ${ }^{15}$

\section{Chapter 2: Can I Have Friends?}

Yes and No. Female friends will do one of two things for you: 1.) Shatter your reality by saying things like "you need to stop being so shallow and look within, you care too much about what people think of you, you spend too much of your money on this face glue, you're a train wreck, and for god sakes, you made the sales girl from Victoria's Secret file for a restraining order!" 2.) Be competition. You can't have other dime pieces walking around, because one of them is inevitably going to be shinier than you and more valuable, and they'll have big thoughts and won't care about what people think because they're all enlightened from that feminism class they took last fall...

For the record, I don't need to be enlightened, as long as my hair is bleached.

So, in my opinion, having "friends" around doesn't do a whole lot for you in terms of the whole perfect feminine being thing. They only bring you down. Unless, of course, you find yourself surrounded by what I like to call "nickel backs," meaning that they're half of what a dime piece looks like and values, and are also terrible at everything they try to do, especially emoting when singing and writing songs that are distinguishable from each other. By surrounding yourself with a bunch of nickel backs, you are going to look, like, a thousand times more amazing, because when compared to a nickel back, let's face it, everyone just somehow seems significantly better. ${ }^{16}$

If you must have friends, this is what I suggest as a possible solution. "But wait!" I hear you cry. ${ }^{17}$ What about the most famed best friend a girl can have? The one that not only dresses her, obsesses over her love life, but also can tell her when the hot bartender guy she has

15. Sheesh, you really are a mess.

16. Nickel backs are now for rent at a Sociopath's Disposable Friendships

Factory near you!

17. Stop crying. You just seem desperate. 
been obsessing over for the past two months isn't feigning disinterest because he's aloof and artistic, but rather, a homosexual?

I am referring to, of course, the famed gay best friend. He'll be your everything when times are rough. He'll be your confidant, your stylist, your sex therapist, and in the movies, your makeover montage partner. He'll even be sassy when you're being absolutely de-lus-ion-al about the fact that he is even into you, I mean, why would he be into you, girlfriend? When you're looking like a soup full of ugly all mixed in with a teaspoon of bitter denial? ${ }^{18}$ The gay best friend is the ideal companion for all of these reasons, and more. He's not competition because he's a guy, and he doesn't have any more of a substantial role because he's only written into the script for comedic relief. His backstory will never be mentioned because he's a minor character in a story which revolves around you!

And it doesn't end there! The gay best friend is also good for harboring intense romantic feelings for, despite the fact that you will never be able to act on them, causing a bizarre one sided tension that typically comes out after a night of heavy drinking, resulting in weeping, tears, awkward hugging, and painful attempts at convincing him to love you, and his promise to never talk to you again. ${ }^{19}$

\section{Chapter 3: Sexuality: Your Crossbow in the Hunger Games of LIFE}

Remember how I said we were starting on the outside and were going to work our way in? Well, we have arrived. Last stop, sexy-town! Population, your uh...um...yeah...

Okay, full disclosure, like most women who can't help but dole out unsolicited sexual/relationship advice, I'm really not sure what's happening down there. But according to several of my sources from a conservative political party in a country that I live in, ${ }^{20}$ there's a lot of evil doings and mischievous shenanigans going on in Lady Town,

18. Line taken from the book The Faux-Homo's Demeaning Guide to Sassy Remarks that Straight People Find Hilarious. All rights reserved.

19. Once again, this is, uh, totally not one of my experiences... But if you're reading this, Kevin, stop avoiding my calls!

20. Ten points to whoever figures out what country I'm referencing! 
mostly bent on warping the space time continuum and killing off Bruce Willis' future self.

Once again, let's not get into technicalities. Rather, let us focus on what goes on between the ears, and the way one must think about one's own sexuality if one wants to achieve perfect feminine being status. ${ }^{21}$ It's simple. One must be two things at the same time: knowledgeable in the ways of the world, whilst acting like you have absolutely no clue, so that it seems like one is as pure as can be, fully equipped with an unsullied chastity, so that it seems that one just happens to know how to do some crazy stuff that very few people are privy to on account of its high level of depravity. ${ }^{22}$

This is the last step to finally achieving perfect feminine being status. For when the perfect feminine being walks, she makes the fellas say "What an enchanting girl. I shall buy her a drink!" and then later they say "Well, that's uh, that's an interesting idea, but we've just met. The dilapidated what-now?" And then murmur embarrassedly, "I'm sorry, you're making me uncomfortable. I'll...uh...just let myself out."

Remember ladies, you're going to want to possess an inner Aphrodite, but it is absolutely paramount that she stays within the privacy of your own mind.

"Remember, repression is the Remember, repression is best medicine!" the best medicine! ${ }^{23}$ If you don't keep her hidden within, purity fairies will come and take the sparkle behind your eyes and replace it with knowing sensuality. Heed my warning; once he knows you actually enjoy something that you were built to enjoy, and once he knows that you're actually as interested in him like he's interested in you, the chase ends! Then, you'll be the one calling after a night of heavy drinking, saying "Hey boy, I'd really like to see you, if you're still even up at this hour, and aren't too tired, and don't think I'm too needy, baby. Cause I'd really like see you right now, if it's you know, not too much, and you aren't seeing anyone else, and are still interested, sweet cakes." ${ }^{24}$

21. Multiple people can do this too.

22. The dilapidated donkey, the gurgling tortoise, and the wild mongoose are some well-known examples.

23. ...If you're a healthy and happy person and wish to change that.

24. In addition to everything else, I am also a master at the sexy talk. 
No guy wants to hear that a girl is attracted to him, trust me. Huge turn off.

Just remember this simple image and you'll do fine. You are a warrior princess, originally raised as a farmer, but whose farm was attacked, and you had to defend it with your greatest weapon, your sexuality, which is your crossbow, hidden underneath your nun's habit and bedazzled sweat pants, where only you can see. But whereas it is also your greatest weapon, when used improperly, it is also your greatest liability, with the power to cause terrible things to happen; both to yourself, and to the female race as we know it, scarring us all of all eternity with your terrible betrayal. ${ }^{25}$

\section{Conclusion: Well, I Tried.}

What have we learned, my fellow females? We have learned several very important things. We have learned what we should look like, what society we should keep, and how we should interpret our sexuality if we are to achieve what we most want: utterly effortless perfection. I am going to be frank with you. It takes a lot more than this simple manual to be a perfect feminine being. It takes dedication, reflection, time, effort, and improvisation on your part. It's a daily process. You have to look inside, see that the person in there is no good, and replace them with my advice and the instructions so dutifully given by our most Holy Media and popular culture, slappings and fleas be upon them. In fact, most of you won't even come close to being a perfect feminine being. Most of you will scoff at me and my advice, and to you I say, well, I tried.

I tried to make you perfect. I tried to make you into the greatest thing that any woman can ever dream of being. But you said no. You said, "Hey Mia, you're completely insane. I hate you a little, occasionally daydream about punching you in the face, and I don't want anything to do with any of this clearly apparent bullshit. You want to strip me of my identity, my friends, my style, you even want me to do this weird ass repression thing when it comes to my sexuality. What the hell is your problem?"

The problem is, my friends, that I am merely doing my best

25 . Not actually true, but it is a nice way to end a chapter! 
to help you achieve perfect feminine being status. To question it is to question ourselves, what we're teaching our children, the storylines we accept when we watch our movies and television, shows, the music we listen to, our stance on politics, and the way in which we interact and relate to one another.

And a perfect feminine being never asks questions. 
BENCIVENGA 
FORBES \& FIFTH 